\title{
LXV. an account of the comparison of various British standards of linear measure
}

\section{Capt. Henry Kater F.R.S.}

To cite this article: Capt. Henry Kater F.R.S. (1821) LXV. an account of the comparison of various British standards of linear measure, Philosophical Magazine Series 1, 58:282, 280-288, DOI: $10.1080 / 14786442108652627$

To link to this article: http://dx.doi.org/10.1080/14786442108652627

册 Published online: 27 Jul 2009.

Submit your article to this journal $\sqsubset \pi$

Цll Article views: 2

Q View related articles $₫$ 
like truth. The continuous attacks of the exhaustless, though weaker, assailant rouse the more gigantic, but intermittent, repellent energies of its opponent. It is a war offensive and defensive. Thus does the contest continue for life with equal success, and at its close remain a drawn battle.

J. MurraY.

LXV. An Account of the Comparison of various British Standards of linear Measure. By Capt. Henry KaTER, F.R.S. छेc.**

IT $\mathrm{HeC}$ The and Measures, recommended in their First Report " for the legal determination of the standard yard, that which was employed by General Roy in the measurement of a Base on Hounslow Heath, as a foundation for the Trigonometrical operations that have been carried on by the Ordnance throughout the country." In consequence of this determination, it became necessary to examine the standard to which the Report alludes, with the intention of subsequently deriving from it a scale of feet and inches.

On referring to the Philosophical Transactions for 1785 , it may be seen in " an Account of the Measurement of a Base on Hounslow Heath," that a brass scale, the property of General Roy (and now in the possession of Henry Browne, Esq. F.R.S.), was taken to the apartments of the Royal Society; and, being there, with the assistance of $\mathrm{Mr}$. Ransden, compared with their standard (both having remained together two days previous to the comparison), the extent of three feet taken from the Society's standard, and applied to General Roy's scale, was found to reach exactly to 36 inches, at the temperature of $65^{\circ}$.

It afterwards appears that points, at the distance of 40 inches from each other, were laid off on a large plank from General Roy's scale, the whole length being 20 feet; and by means of this plank the length of the gluss rods was determined, with which the base on Hounslow Heath was measured.

In the Philosophical Transactions for 1795, it is stated, that $\dot{M}$. Ramsden compared his brass standard with that belonging to the Royal Society, after they had remained together about 24 hours, when "they were found to be precisely of the same length." Brass points were then inserted in the upper surface of a cast-iron triangular bar of 21 feet in length, from Mr. Ramsden's standard, at the distance of 40 inches from each other; the

* From the Transactions of the Royal Society for 1821, Part I. 
whole length of 20 feet being laid off on those points in the temperature of $54^{\circ}$.

By means of this bar, the length of the hundred feet steel chain was determined with which the base on Hounslow Heath was re-measured, and was found to be only about $2 \frac{3}{4}$ inches greater than the measurement with the glass rods.

The standard scale used by Mr. Ramsden in laying off the points on the iron bar, is, it seems, no longer to be found; but foon the declared equality of both this and General Roy's standard with that of the Royal Society, and the near agreement of the two separate measurements of the base with the glass rods and with the steel chain, one might have been tempted to consider General Roy's scale as precisely similar to Mr. Ramsden's, and as offering the best source from which the national standard yard might be obtained.

The spirit, however, of the recommendation of the Commissioners of Weights and Measures, appearing to be, that the standard yard should be derived from the base of the Trigonometrical Survey, I thought it preferable to proceed a step higher, and to obtain a distance of 40 inches from the iron bar jtself, which could afterwards be employed in any manner that might be found most eligible.

In order to obviate the necessity of an allowance for temperature, I caused a triangular bar of cast-iron to be made, of the same dimensions as Mr. Ramsden's, except as to length. Gold pins were inserted near the extremities of this bar at the distance of 40 inches from each other, on which were to be drawn fine lines, comprising one-sixth part of the length of the 20 feet bar.

The apparatus used for tracing the lines on the gold pins, is essentially different from that commonly employed. The cutting point is elevated by means of an inclined plane, and is then carried through a distance equal to the length of the line to be traced. On drawing back a part of the apparatus, the extremity of which acts upon the inclined plane, the point descends by its own weight until it wholly rests upon the surface of the bar; the motion being then continued, the frame and cutting point are drawn along together, without the possibility of lateral deviation; and the point describes a line, the length of which may, by a certain contrivance, be regulated at, pleasure, and its strength determined by repeating the operation. This very neat and important invention is due to M.Fortin of Paris, and was communicated to me by M. Arago, whose liberal mind knows no reserve on scientific subjects. I have varied the arrangement of M. Fortin, so as to bring the cutting point under a microscope furnished with cross wires, having an adjustment, by means of which their in-
Vol.58. No. 282. Oct. 1821.
$\mathrm{N}$ n
tersection 
tersection can be brought to the line traced by the cutting point. T'his I consider to be an essential improvement, as no, accidental derangement of the cutting frame can take place without its being inmediately perceptible; and the apparatus may be conveniently applied to the division of straight lines or circles, in the manner I have described in the Philosophical Transactions for 1814.

The micrometer microscopes, used in the comparison of the different standards, were those employed in the determination of the length of the seconds pendulum, the description of which may be seen in the Philosophical. Transactions for 1818. But as the arrangement of $\mathrm{Mr}$. Ramsden's bar, required that the support to which the microscopes were attached should rest on its surface, some other form of the beam carrying them became necessary for this purpose.

A board was prepared of well seasoned mahogany, 36 inches long, 3 inches wide, and $\frac{3}{4}$ thick, and an edge bar of mahogany $3 \frac{1}{2}$ inches wide and $1 \frac{1}{4}$ thick, was firmly fixed along the middle of it lengthwise, which most effectually prevented the possibility of flexure. To the extremities of this edge bar, and projecting beyond them, the microscopes were fixed, their cross wires being about 40 inehes asunder. By this arrangement, the very important advantage was ensured, that the apparatus being laid on a plain surface, such as a scale, and the microscopes adjusted to distinct vision, on placing it on another plane scale, the object glasses of the microscopes would be precisely at the same distance from this last surface as they were from that to which they were applied in the first instance,' and consequently no error could arise from parallax.

A piece of very thin brass, usually called latin brass, was bent round the edges of the 40 -inch bar, so that the upper surface of the bar was ia perfect contact with the brass, the side pressure being just sufficient to prevent any change of position in the brass, unless when moved along the bar by hand. A fine line, about the eighth of an inch long, was now drawn on one of the gold pins at right angles to the bar, and a similar line was traced on the piece of brass, which was placed so as to cover the other gold pin. The intersection of the cross wires of the tracing microscope was carefully adjusted to this last line.

Mr. Ramsden's bar, upon his decease, became the property of Mr. Berge, whose successor, Mr. Worthington, kindly granted me access to it, and facilitated my examination by every assistance in his power. The bar was placed in his workshop on tressels, and its surface carefully brought into the same plane, which was ascertained by stretching a threal from end to end. 
The 40-inch bar was laid near Mr. Ramsden's bar, on the 12th of April 1820, and a thermometer placed upon it. Three thermometers were also arranged at equal distances along Mr. Ramsden's bar.

On the 13th of April I commenced my examination. The intersection of the wires of the one microscope being placed on the centre of the left hand dot, the intersection of the wires of the other microscope was brought, by means of its micrometer screw, to the centre of the, right hand dot, and the reading of the micrometer registered. In this manner the six intervals of Mr. Ramsden's bar were compared in succession. It may be necessary to remark, that as the microscopes invert, the readings are to be taken in a contrary sense, the higher number indicating defect, and vice versâ.

\begin{tabular}{|c|c|c|}
\hline & Readings. & Thermometers. \\
\hline $\begin{array}{l}\text { Ist interval. } \\
2 \mathrm{~d} \\
3 \mathrm{~d} \\
4 \text { th } \\
5 \text { th } \\
6 \text { th }\end{array}$ & $\begin{array}{l}29 \cdot 5 \\
10 \cdot 0 \\
10 \cdot 0 \\
16 \cdot 5 \\
10 \cdot 0 \\
19 \cdot 0\end{array}$ & 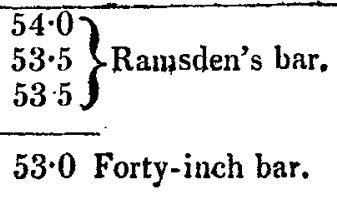 \\
\hline Mean & $15 \cdot 9$ & \\
\hline
\end{tabular}

The difference of temperature of the two bars, being so small, may safely be neglected.

The micrometer microscope was now set to $15 \cdot 9$ divisions, and the apparatus being laid on the 40 -inch bar, the intersection of the wires of the left hand microscope was brought to the middle of the line on the gold pins, and the piece of latin brass was moved along the bar, till the middle of the line drawn upon it appeared in the intersection of the wires of the micrometer microscope. The whole having been carefully examined, the micrometer microscopes were withdrawn.

The tracing microscope was next brought over the 40 -inch bar, and placed so that the intersection of its wires appeared upon the middle of the line traced upon the brass; the brass was then slid away, and a line drawn with the cutting point upon the gold surface.

I had next to compare the distance thus obtained, with the mean of the six intervals on Mr. Ramsden's bar. 
First Comparison.

The four thermometers being at $54^{\circ}$, the following readings were taken.

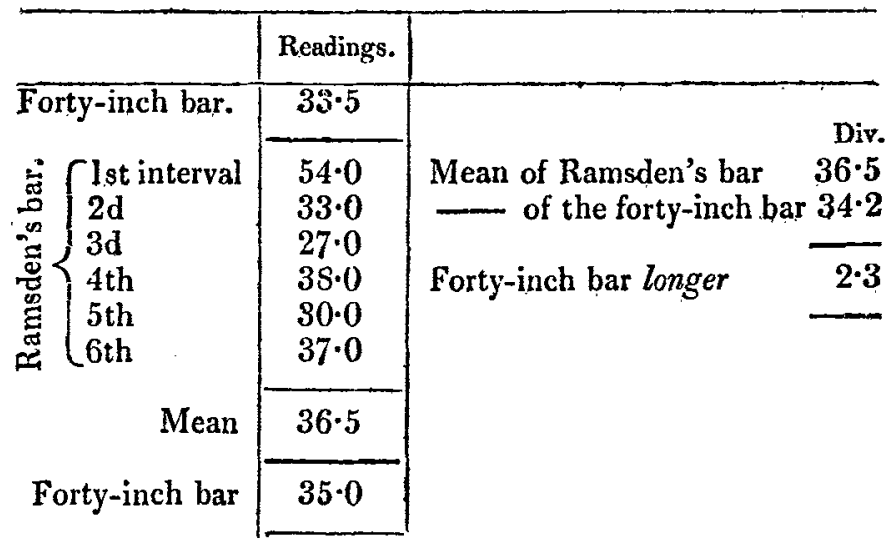

Second Comparison. Thermometers as lefore.

\begin{tabular}{|c|c|c|c|}
\hline & Readings. & & \\
\hline Forty-inch bar. & $36 \cdot 0$ & \multirow{4}{*}{$\begin{array}{l}\text { Mean of Ramsden's bar } \\
\text { Forty-inch bar longer. }\end{array}$} & \\
\hline 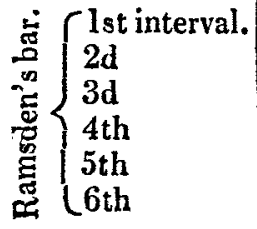 & $\begin{array}{l}54 \cdot 5 \\
31 \cdot 0 \\
26 \cdot 0 \\
40 \cdot 0 \\
35 \cdot 5 \\
40 \cdot 0\end{array}$ & & $\begin{array}{r}\text { Div. } \\
37 \cdot 8 \\
35 \cdot 5 \\
2 \cdot 3\end{array}$ \\
\hline Mean & $37 \cdot 8$ & & \\
\hline Forty-inch bar & $35 \cdot 0$ & & \\
\hline
\end{tabular}


Third Comparison. Thermometers as before.

\begin{tabular}{|c|c|c|c|}
\hline & Readings. & & \\
\hline Forty-inch bar & $35 \cdot 0$ & \multirow{4}{*}{$\begin{array}{l}\text { Mean of Ramsden's bar } \\
\text { Forty-iueh bar longer }\end{array}$} & \\
\hline $\begin{array}{l}\text { Ist interval } \\
2 \mathrm{~d} \\
3 \mathrm{~d} \\
4 \mathrm{th} \\
5 \mathrm{th} \\
6 \mathrm{th}\end{array}$ & $\begin{array}{l}58 \cdot 7 \\
30 \cdot 0 \\
31 \cdot 0 \\
44 \cdot 0 \\
34 \cdot 0 \\
40 \cdot 0\end{array}$ & & $\begin{array}{r}\text { Div. } \\
39 \cdot 6 \\
35 \cdot 6 \\
4 \cdot 0\end{array}$ \\
\hline Meạn & $39 \cdot 6$ & & \\
\hline Forty-inch bar & $36: 2$ & & \\
\hline
\end{tabular}

By the mean of these comparisons, it appeared that the fortyinch bar was too long 2.9 divisions of the micrometer, or $\cdot 000124$ of an inch *.

The preceding measures were taken from the middle of the lines on the gold pins; but as it was found that these lines were not quite parallel, this accidental circumstance afforded a method, of which $I$ availed myself, to attain a greater degree of accuracy.

The deviation of the two lines was obtained by measuring the difference of the distances of their extremities, and by the mean of six comparisons was found to be $16 \cdot 6$ divisions.

Now, as this is the deviation due to the whole length of the lines, they will have approaehed each other $2 \cdot 9$ divisions, at about one-sixth part of their length, feekoning from their most distant extremities.

This portion of the line being estimated, transverse lines were drawn, indicating the points from which future measurements were to be taken.

On the 14th of April I resumed my comparisons.

Conceiving that it would be preferable to ascertain the difference between some one interval and the mean of all the intervals of Mr. Ramsden's bar, and afterwards to compare such interval with the forty-inch bar, I now directed my attention to this object.

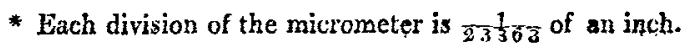


An Account of the Comparison of

Fourth Comparison. Thermometers $52^{\circ} \cdot 5$.

\begin{tabular}{|c|c|}
\hline & Readings. \\
\hline $\begin{array}{l}\text { Ist interval } \\
\text { 2d } \\
3 \text { d } \\
4 \text { th } \\
\text { 5th } \\
6 \text { th }\end{array}$ & $\begin{array}{l}99 \cdot 0 \\
78 \cdot 0 \\
73 \cdot 0 \\
83 \cdot 0 \\
82 \cdot 0 \\
83 \cdot 0\end{array}$ \\
\hline Mean & $83 \cdot 0$ \\
\hline
\end{tabular}

15th April. Fifth Comparison. Thermometers $56^{\circ}$.

\begin{tabular}{|c|c|}
\hline & Readings. \\
\hline $\begin{array}{l}\text { 1st interval } \\
2 \mathrm{~d} \\
3 \mathrm{~d} \\
\text { 4th } \\
5 \text { th } \\
6 \text { th }\end{array}$ & $\begin{array}{r}107 \cdot 0 \\
81 \cdot 0 \\
76 \cdot 0 \\
89 \cdot 0 \\
77 \cdot 0 \\
87 \cdot 0\end{array}$ \\
\hline Mean & $86 \cdot 1$ \\
\hline
\end{tabular}

Sixth Comparison. Thermometers $56^{\circ}$.

\begin{tabular}{|c|c|}
\hline & Readings. \\
\hline $\begin{array}{l}\text { 1st interval } \\
2 \mathrm{~d} \\
3 \mathrm{~d} \\
4 \mathrm{th} \\
5 \text { th } \\
6 \text { th }\end{array}$ & $\begin{array}{r}107 \cdot 0 \\
80 \cdot 0 \\
79 \cdot 0 \\
82 \cdot 0 \\
75 \cdot 0 \\
83 \cdot 5\end{array}$ \\
\hline Mean & $84 \cdot 4$ \\
\hline
\end{tabular}

On examining the preceding comparisons, it may be perceived that the readings of the sixth interval differ very little from those of the mean of the whole bar. 
various British Standards of linear Measure.

\begin{tabular}{|c|c|c|}
\hline $\begin{array}{c}\text { Readings of the sixth Mean readings of all } \\
\text { interval. } \\
\text { the intervals. }\end{array}$ & $\begin{array}{c}\text { Value of the sixth } \\
\text { interval + or -. }\end{array}$ \\
\hline 37.0 & 36.5 & -0.5 \\
40.0 & 37.8 & -2.2 \\
40.0 & 39.6 & -0.4 \\
83.0 & 83.0 & -0.0 \\
87.0 & 86.1 & -0.9 \\
83.5 & 84.4 & +0.9 \\
\hline & Mean & -0.5 \\
\hline
\end{tabular}

The sixth interval, therefore, is too short 0.5 of a division.

This interval was now compared with the forty-inch bar, the thermometers being at $57^{\circ}$; the microscopes were transferred from one bar to the other alternately.

\begin{tabular}{|c|c|}
\hline $\begin{array}{c}\text { Readings of the sixth } \\
\text { interval. }\end{array}$ & $\begin{array}{c}\text { Readings of the forty- } \\
\text { inch bar. }\end{array}$ \\
\hline $81 \cdot 5$ & $85 \cdot 0$ \\
$85 \cdot 3$ & $85 \cdot 0$ \\
$82 \cdot 7$ & 86.0 \\
$83 \cdot 0$ & $83 \cdot 0$ \\
$83 \cdot 5$ & $83 \cdot 0$ \\
$83 \cdot 0$ & $82 \cdot 0$ \\
$82 \cdot 5$ & $82 \cdot 6$ \\
$82 \cdot 2$ & $82 \cdot 6$ \\
$82 \cdot 5$ & $81 \cdot 3$ \\
82.0 & $81 \cdot 5$ \\
82.7 & $82 \cdot 5$ \\
82.0 & $81 \cdot 3$ \\
\hline $82 \cdot 7$ & $83 \cdot 0$ \\
\hline
\end{tabular}

From this it appears, that the forty-inch bar is storler than the sixth interval 0.3 of a division; and as the sixth interval was found to be shorter than the mean of all the intervals $0 \cdot \dot{5}$ of a division, the result of the whole is, that the forty-inch bar is shorter than one-sixth of Ramsden's bar 0.8 of a division, or .000034 of an inch.

I may here remark, that the differences observable between the results of the various comparisons of the intervals of Ramsden's bar, may be attributed to the large size and imperfect state of most of the dots ; those bounding the sixth interval are fortunately the least injured. 
Having thus obtrined the value of the standard, from which the chain used in the Trigonometrical Surrey was actually laid off, I next proceeded to comprate this with General Roy's and Sir Gcorge Shuckburgh's scales.

[To be continued.]

LXVI. On Shat Cartidges. By Mr. Joseph Stervens.

To Dr. Tilloch.

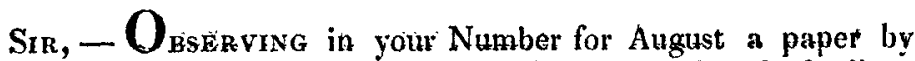
A Correspondent in India, on the use of shot cartridges for fowlingpieces; I beg to observe that I adopted the use of such cartridges in the year 1793 , and myself and several friends have contiutued to use them ever since. From the year 1793 to 1804 , they were several times taken to India by a friend of mine (who was a Purser in that service) : whether he consumed the whole, or disposed of a part with his investment, I know not: certain it is they were not returned to England. Cartridges containing hoth powder and shot were introduced at the same time, and in many instances have been foumd very advantageous. And as your Correspondent has omitted to describe the chief utility of shot cartridges, I shall here describe both, and state a few out of many experiments made by myself and others for that purpose.

The chief advantages of shot cartridges are, the prevention of the barrel from leading, and at the same time actually assisting in cleaning it on every discharge. It is well known that in order to make shot bright and handsome, as it is termed, a considerable quantity of black lead is used, a portion of which is at every discharge deposited in the inside of the barret, and so closely does it adhere that the ordinary mode of cleansing is not sufficient to remove it; and I have within a few days seen a barrel so leaded, as to materially impede its projectile force, divert the shot from its rectilineal course, and defirer it in irregntar chasters, leaving spaces trear the cerntre of the charge at forty yards distance, four or five inches diameter ; besides which, the lead frotn the shot, together witf the deposit of the powder, actually so contracts the bartel itrmiediately in front of the charge, that (althotrgh the gun has been cleaned in the ordinary way) I have known a sound barrel blown to pieces from this cause alone, which the use of shot cattridges would have prevented. Yet 1 do not consider them indispensable, nor have I adopted thetn generally, except where a quick strccession of discharges is essential. The operationt of cleansing at every discharge is thus performed : the cartridge which nearly fits the bore when put in, is enlarged. by the explosion 